\title{
Monotonicity of Eventually Positive Solutions for a Second Order Nonlinear Difference Equation
}

\author{
Huiqin Chen, ${ }^{1}$ Zhen Jin, ${ }^{2}$ and Shugui Kang ${ }^{1}$ \\ ${ }^{1}$ School of Mathematics and Computer Sciences, Datong University, Datong, Shanxi 037009, China \\ ${ }^{2}$ Department of Mathematics, North University of China, Taiyuan, Shanxi 030051, China \\ Correspondence should be addressed to Shugui Kang; dtkangshugui@126.com
}

Received 7 October 2012; Revised 27 December 2012; Accepted 19 January 2013

Academic Editor: Tailei Zhang

Copyright (c) 2013 Huiqin Chen et al. This is an open access article distributed under the Creative Commons Attribution License, which permits unrestricted use, distribution, and reproduction in any medium, provided the original work is properly cited.

We derive several sufficient conditions for monotonicity of eventually positive solutions on a class of second order perturbed nonlinear difference equation. Furthermore, we obtain a few nonexistence criteria for eventually positive monotone solutions of this equation. Examples are provided to illustrate our main results.

\section{Introduction}

The theory of difference equations and their applications have received intensive attention. In the last few years, new research achievements kept emerging (see [1-7]). Among them, in [3], Saker considered the second order nonlinear delay difference equation

$$
\Delta\left(p_{n} \Delta x_{n}\right)+q_{n} f\left(x_{n-\sigma}\right)=0, \quad n \geqslant 0 .
$$

Saker used the Riccati transformation technique to obtain several sufficient conditions which guarantee that every solution of (1) oscillates or converges to zero. In [4], Rath et al. considered the more general second order equations

$$
\begin{array}{cc}
\Delta\left(r_{n} \Delta\left(y_{n}-p_{n} y_{n-m}\right)\right)+q_{n} G\left(y_{n-k}\right)=0, & n \geqslant 0, \\
\Delta\left(r_{n} \Delta\left(y_{n}-p_{n} y_{n-m}\right)\right)+q_{n} G\left(y_{n-k}\right)=f_{n}, & n \geqslant 0 .
\end{array}
$$

They found necessary conditions for the solutions of the above equations to be oscillatory or tend to zero. Following this trend, this paper is concerned with the second order perturbed nonlinear difference equation

$$
\Delta\left(a_{n} \Delta x_{n}\right)+P\left(n, x_{n}, x_{n+1}\right)=Q\left(n, x_{n}, \Delta x_{n}\right), \quad n \geqslant 0,
$$

where $\left\{a_{n}\right\}$ is a positive sequence, $P, Q: N \times R^{2} \rightarrow R$ are two continuous functions, and $\Delta$ is the forward difference operator defined as $\Delta x_{n}=x_{n+1}-x_{n}$.
In [8], Li and Cheng considered the special case of (3)

$$
\Delta\left(p_{n-1} \Delta x_{n-1}\right)+q_{n} f\left(x_{n}\right)=0, \quad n \geqslant 0 .
$$

They got the sufficient conditions for asymptotically monotone solutions of (4). Enlightened by $[8,9]$, in this paper, we derive several sufficient conditions for monotonicity of eventually positive solutions on (3) and obtain a few nonexistence criteria for eventually positive monotone solutions of (3). Our results improve and generalize results in [8]. We also provide examples to illustrate our main results.

For convenience, these essential conditions used in main results are listed as follows:

$\left(H_{1}\right)$ there exists a continuous function $f: R \rightarrow R$ such that $x f(x)>0$ for all $x \neq 0$;

$\left(H_{2}\right) f$ is a derivable function and $f^{\prime}(x) \geqslant 0$ for $x \neq 0$;

$\left(H_{3}\right)$ there exist two sequences $\left\{p_{n}\right\}$ and $\left\{q_{n}\right\}$, such that $P\left(n, x_{n}, x_{n+1}\right) / f\left(x_{n+1}\right) \geqslant p_{n}$ and $Q\left(n, x_{n}, \Delta x_{n}\right) /$ $f\left(x_{n+1}\right) \leqslant q_{n}$ for $x_{n} \neq 0$;

$\left(H_{4}\right) \sum_{n=n_{0}}^{\infty} 1 / a_{n}=+\infty, n_{0}$ is a positive integral number,

where $a_{n}, P\left(n, x_{n}, x_{n+1}\right)$ and $Q\left(n, x_{n}, \Delta x_{n+1}\right)$ are all in (3). 


\section{Main Results}

We first state a result which relates a positive sequence and a positive nondecreasing function. Its proof can be found in [8].

Lemma 1 (see [8]). Let $f(x)$ be a positive nondecreasing function defined for $x>0$. Let $\left\{x_{k}\right\}$ be a real sequence such that $x_{k}>0$ for $i \leqslant k \leqslant j+1$. Then

$$
\sum_{k=i}^{j} \frac{\Delta x_{k}}{f\left(x_{k+1}\right)} \leqslant \int_{x_{i}}^{x_{j+1}} \frac{d u}{f(u)} \leqslant \sum_{k=i}^{j} \frac{\Delta x_{k}}{f\left(x_{k}\right)} .
$$

Theorem 2. Suppose that conditions $\left(H_{1}\right)-\left(H_{4}\right)$ hold, $p_{n}$ and $q_{n}$ satisfy the following conditions:

$$
\begin{aligned}
& \left(H_{5}\right) \sum_{s=n_{0}}^{\infty}\left(p_{s}-q_{s}\right)<+\infty ; \\
& \left(H_{6}\right) \lim \inf _{n \rightarrow \infty} \sum_{s=n_{0}}^{n}\left(p_{s}-q_{s}\right) \geqslant 0
\end{aligned}
$$

for all $n_{0}$. Then eventually positive solutions of (3) are eventually monotone increasing.

Proof. Suppose that $\left\{x_{n}\right\}$ is a positive solution of (3), say $x_{n}>$ 0 for $n>N>n_{0}$. If conclusion cannot hold, without any loss of generality, assume $\Delta x_{N} \leqslant 0$, in view of (3) and conditions, we have

$$
\begin{aligned}
\Delta\left(\frac{a_{n} \Delta x_{n}}{f\left(x_{n}\right)}\right) & =\frac{\Delta\left(a_{n} \Delta x_{n}\right)}{f\left(x_{n+1}\right)}-\frac{a_{n}\left(\Delta x_{n}\right)^{2} f^{\prime}\left(x_{n}+\theta \Delta x_{n}\right)}{f\left(x_{n}\right) f\left(x_{n+1}\right)} \\
& \leqslant q_{n}-p_{n} \quad(0<\theta<1),
\end{aligned}
$$

by summing (6) from $N$ to $n-1$, then

$$
\frac{a_{n} \Delta x_{n}}{f\left(x_{n}\right)} \leqslant \frac{a_{N} \Delta x_{N}}{f\left(x_{N}\right)}-\sum_{s=N}^{n-1}\left(p_{s}-q_{s}\right) .
$$

Making use of condition $\left(H_{6}\right)$, we know $\Delta x_{n}<0$ for $n \geqslant N$. Summing (3) and using $\left(\mathrm{H}_{3}\right)$, we have

$$
\begin{aligned}
a_{n} \Delta x_{n} \leqslant & a_{N} \Delta x_{N}-\sum_{s=N}^{n-1} f\left(x_{s+1}\right)\left(p_{s}-q_{s}\right) \\
= & a_{N} \Delta x_{N}-f\left(x_{n+1}\right) \sum_{s=N}^{n-1}\left(p_{s}-q_{s}\right) \\
& +\sum_{s=N}^{n-1} \Delta f\left(x_{s}\right)\left(\sum_{t=N}^{s-1}\left(p_{t}-q_{t}\right)\right) \\
\leqslant & a_{N} \Delta x_{N} .
\end{aligned}
$$

By summing (8), we then see that

$$
x_{n+1} \leqslant x_{N}+a_{N} \Delta x_{N} \sum_{s=N}^{n} \frac{1}{a_{s}} \longrightarrow-\infty \quad(\text { as } n \longrightarrow \infty),
$$

which contradicts the fact $x_{n}>0$. The proof is complete.
Example 3. Consider the difference equation

$$
\begin{aligned}
& \Delta\left(\frac{\Delta x_{n}}{n^{2}}\right)+x_{n+1}\left(r\left(n, x_{n}\right)+\frac{1}{n^{2}(n+1)}-\frac{1}{(n+1)^{3}}\right) \\
& =x_{n+1} r\left(n, x_{n}\right), \quad n \geqslant 0,
\end{aligned}
$$

where $r\left(n, x_{n}\right)$ is any function of $n$ and $x_{n}$. By taking $f(x)=x$, we have

$$
\begin{gathered}
\frac{P\left(n, x_{n}, x_{n+1}\right)}{f\left(x_{n+1}\right)}=r\left(n, x_{n}\right)+\frac{1}{n^{2}(n+1)}-\frac{1}{(n+1)^{3}}=p_{n}, \\
\frac{Q\left(n, x_{n}, \Delta x_{n}\right)}{f\left(x_{n+1}\right)}=r\left(n, x_{n}\right)=q_{n} .
\end{gathered}
$$

So conditions of Theorem 2 hold. By Theorem 2, (10) has a positive monotone increasing solution $\left\{x_{n}\right\}=\{n\}$.

Theorem 4. If conditions $\left(H_{1}\right)-\left(H_{4}\right)$ hold, there exist $M>0$ and $j>n_{0}$ for $n_{0} \geqslant M$ such that

$$
\limsup _{n \rightarrow \infty} \sum_{k=j}^{n} \frac{1}{a_{k}} \sum_{s=n_{0}}^{k-1}\left(p_{s}-q_{s}\right)>0 .
$$

Then eventually positive solutions $\left\{x_{n}\right\}$ of (3) are eventually monotone increasing or $\lim \inf _{n \rightarrow \infty} x_{n}=0$.

Proof. Suppose $\left\{x_{n}\right\}$ is a positive solution of (3), there exists $N>n_{0}$ such that $x_{n}>0$ for $n>N$. Let $\Delta x_{N} \leqslant 0$, and

$$
\limsup _{n \rightarrow \infty} \sum_{k=j}^{n} \frac{1}{a_{k}} \sum_{s=N}^{k-1}\left(p_{s}-q_{s}\right)>0, \quad j>N .
$$

If $\lim _{\inf } x_{n \rightarrow \infty} x_{n} \neq 0$, then there exist $T \geqslant N$ and a number $\alpha>0$ such that $x_{n}>\alpha>0$ for $n \geqslant T$; in view of (7), we get

$$
\frac{\Delta x_{n}}{f\left(x_{n}\right)} \leqslant \frac{a_{N} \Delta x_{N}}{f\left(x_{N}\right)} \cdot \frac{1}{a_{n}}-\frac{1}{a_{n}} \sum_{s=N}^{n-1}\left(p_{s}-q_{s}\right) .
$$

Summing (14) and making use of Lemma 1, we know

$$
\begin{aligned}
\int_{x_{j}}^{\alpha} \frac{d u}{f(u)} & \leqslant \int_{x_{j}}^{x_{n+1}} \frac{d u}{f(u)} \\
& \leqslant \frac{a_{N} \Delta x_{N}}{f\left(x_{N}\right)} \sum_{k=j}^{n} \frac{1}{a_{k}}-\sum_{k=j}^{n} \frac{1}{a_{k}} \sum_{s=N}^{k-1}\left(p_{s}-q_{s}\right) .
\end{aligned}
$$

By $\left(H_{4}\right)$, the right side of (15) tends to $-\infty$ as $n \rightarrow \infty$, whereas the left side is finite. This contradiction completes our proof.

Example 5. Consider the difference equation

$$
\Delta\left(\frac{\Delta x_{n}}{\sqrt{n}}\right)+\frac{x_{n+1}}{\sqrt{n}}=\frac{\sqrt{n+2}}{n+1} x_{n+1}, \quad n \geqslant 0 .
$$

By taking $f(x)=x$, we have $P\left(n, x_{n}, x_{n+1}\right) / f\left(x_{n+1}\right)=$ $1 / \sqrt{n}=p_{n}, Q\left(n, x_{n}, \Delta x_{n}\right) / f\left(x_{n+1}\right)=\sqrt{n+2} / n+1=q_{n}$. So conditions of Theorem 4 hold. By Theorem 4 , (16) has a positive monotone increasing solution $\left\{x_{n}\right\}=\{\sqrt{n}\}$. 
Theorem 6. If conditions $\left(H_{1}\right)-\left(H_{3}\right)$ hold, and

$$
\liminf _{n \rightarrow \infty} \frac{1}{a_{n}} \sum_{s=n_{0}}^{n-1}\left(p_{s}-q_{s}\right)>0
$$

holds for all $n_{0}$. Then eventually positive solutions $\left\{x_{n}\right\}$ of (3) are eventually monotone increasing or eventually monotone decreasing and $\lim _{n \rightarrow \infty} x_{n}=0$.

Proof. Suppose $\left\{x_{n}\right\}$ is a positive solution of (3), there exists $N>n_{0}$ such that $x_{n}>0$ for $n>N$. Let $\Delta x_{N} \leqslant 0$ and $\lim \inf _{n \rightarrow \infty} 1 / a_{n} \sum_{s=N}^{n-1}\left(p_{s}-q_{s}\right)>0$, then there exists $\beta>0$ such that

$$
\frac{1}{a_{n}} \sum_{s=N}^{n-1}\left(p_{s}-q_{s}\right) \geqslant \beta>0, \quad n \geqslant N
$$

From (7), we have

$$
\Delta x_{n} \leqslant-f\left(x_{n}\right) \cdot \frac{1}{a_{n}} \sum_{s=N}^{n-1}\left(p_{s}-q_{s}\right) \leqslant-\beta f\left(x_{n}\right)<0, \quad n>N .
$$

If $\lim _{n \rightarrow \infty} x_{n} \neq 0$, then there exists $c>0$ such that $x_{n} \geqslant c>0$. There is no harm in assumption $x_{n} \geqslant c$ for $n \geqslant N$. Summing (19), we obtain

$$
c \leqslant x_{n+1} \leqslant x_{N}-(n+1-N) \beta f(c) \longrightarrow-\infty \quad(n \longrightarrow \infty),
$$

which is a contrary. The proof is complete.

Example 7. Consider the difference equation

$$
\Delta\left(n^{2} \Delta x_{n}\right)+x_{n+1}\left(r\left(n, x_{n}\right)+\frac{1}{n+2}\right)=x_{n+1} r\left(n, x_{n}\right)
$$

where $r\left(n, x_{n}\right)$ is any function of $n$ and $x_{n}$. By taking $f(x)=x$, we have

$$
\begin{gathered}
\frac{P\left(n, x_{n}, x_{n+1}\right)}{f\left(x_{n+1}\right)}=r\left(n, x_{n}\right)+\frac{1}{n+2}=p_{n}, \\
\frac{Q\left(n, x_{n}, \Delta x_{n}\right)}{f\left(x_{n+1}\right)}=r\left(n, x_{n}\right)=q_{n} .
\end{gathered}
$$

So conditions of Theorem 6 hold. By Theorem 6, (21) has a monotone decreasing positive solution $\left\{x_{n}\right\}=\{1 / n\}$.

Theorem 8. If conditions $\left(H_{1}\right)-\left(H_{3}\right)$ hold and

$$
\begin{aligned}
& \left(H_{7}\right) \lim \sup _{n \rightarrow \infty} \sum_{s=k}^{n} 1 / a_{s} \sum_{t=n_{0}}^{s-1}\left(p_{t}-q_{t}\right)=+\infty ; \\
& \left(H_{8}\right) \text { for all } \varepsilon>0, \int_{0}^{\varepsilon} d u / f(u)<+\infty .
\end{aligned}
$$

Then eventually positive solutions of (3) are eventually monotone increasing.
Proof. Suppose $x_{n}>0$ for $n>N>n_{0},\left\{x_{n}\right\}$ is a solution of (3), and lim $\sup _{n \rightarrow \infty} \sum_{s=k}^{n} 1 / a_{s} \sum_{t=N}^{s-1}\left(p_{t}-q_{t}\right)=\infty$. If the result does not hold, without any loss of generality, assume $\Delta x_{N} \leqslant 0$. In view of (7), we see that

$$
\begin{aligned}
\frac{\Delta x_{n}}{f\left(x_{n}\right)} & \leqslant \frac{a_{N} \Delta x_{N}}{f\left(x_{N}\right)} \cdot \frac{1}{a_{n}}-\frac{1}{a_{n}} \sum_{t=N}^{n-1}\left(p_{t}-q_{t}\right) \\
& \leqslant-\frac{1}{a_{n}} \sum_{t=N}^{n-1}\left(p_{t}-q_{t}\right) .
\end{aligned}
$$

Summing (23) and using Lemma 1, we know

$$
\int_{x_{k}}^{x_{n+1}} \frac{d u}{f(u)} \leqslant \sum_{s=k}^{n} \frac{\Delta x_{s}}{f\left(x_{s}\right)} \leqslant-\sum_{s=k}^{n} \frac{1}{a_{s}} \sum_{t=N}^{s-1}\left(p_{t}-q_{t}\right) .
$$

This is a contradiction. The proof is complete.

Remark 9. In Theorems 2 and 4, condition $\left(H_{4}\right)$ is essential; that is, the series with positive terms $\sum_{n=n_{0}}^{\infty} 1 / a_{n}$ is divergent, but it is not required in Theorems 6 and 8 .

Remark 10. The eventually positive solutions in Theorems 4 and 8 are increasing it is not necessarily so in Theorem 6 .

Next, we will derive several nonexistence criteria for eventually positive monotone solutions of (3).

Theorem 11. If conditions $\left(H_{1}\right)-\left(H_{3}\right)$ hold and

$$
\limsup _{n \rightarrow \infty} \sum_{k=1}^{n}\left(p_{k}-q_{k}\right)=+\infty
$$

Then, (3) cannot have any eventually positive monotone increasing solutions.

Proof of Theorem 11 is obvious. If $x_{n}>0$ is an eventually positive increasing solution, by means of conditions, (7) is a contrary.

Theorem 12. If conditions $\left(H_{1}\right)-\left(H_{3}\right)$ hold, and there is a nonnegative and nondegenerate sequence $\left\{\varphi_{n}\right\}$ such that

$$
\limsup _{n \rightarrow \infty} \frac{\sum_{k=n_{0}}^{n} \varphi_{k+1} / a_{k} \sum_{s=n_{0}}^{k-1}\left(p_{s}-q_{s}\right)}{\sum_{k=n_{0}}^{n} \varphi_{k+1} / a_{k}}=\infty
$$

holds for all $n_{0}$. Then, (3) cannot have any eventually positive nondecreasing solutions.

Proof. Suppose that $\left\{x_{n}\right\}$ is a positive solution of (3), there exists $N>n_{0}$ such that $x_{n}>0$ and $\Delta x_{n} \geqslant 0$ for $n>N$. Multiplying (7) by $\varphi_{n+1} / a_{n}$, we have

$$
\frac{\varphi_{n+1} \Delta x_{n}}{f\left(x_{n}\right)}+\frac{\varphi_{n+1}}{a_{n}} \sum_{s=N}^{n-1}\left(p_{s}-q_{s}\right) \leqslant \frac{\varphi_{n+1}}{a_{n}} \cdot \frac{a_{N} \Delta x_{N}}{f\left(x_{N}\right)} .
$$

So we obtain

$$
\sum_{k=N}^{n} \frac{\varphi_{k+1}}{a_{k}} \sum_{s=N}^{k-1}\left(p_{s}-q_{s}\right) \leqslant \frac{a_{N} \Delta x_{N}}{f\left(x_{N}\right)} \sum_{k=N}^{n} \frac{\varphi_{k+1}}{a_{k}} .
$$

This is contrary to our condition. The proof is complete. 
Theorem 13. If $\left(H_{1}\right)$ and $\left(H_{3}\right)$ hold, $\left\{a_{n}\right\}$ is a nondecreasing sequence, $f(x)$ is a nondecreasing function, and there is a nonnegative sequence $\left\{\varphi_{n}\right\}$, where $\left\{\Delta \varphi_{n}\right\}$ is bounded, and

$$
\begin{aligned}
& \left(H_{9}\right) \lim _{n \rightarrow \infty} \sum_{s=n_{0}}^{n-1} \varphi_{s+1}\left(p_{s}-q_{s}\right) / a_{s+1}=+\infty \text { for all } n_{0} ; \\
& \left(H_{10}\right) 0<\int_{\varepsilon}^{+\infty} d u / f(u)<+\infty, \varepsilon>0 .
\end{aligned}
$$

Then, (3) cannot have any eventually positive monotone increasing solutions.

Proof. Suppose that $\left\{x_{n}\right\}$ is a solution of (3), and there exists $N>n_{0}$ such that $x_{n}>0$ and $\Delta x_{n}>0$ for $n>N$. Multiplying (3) by $\varphi_{n+1} / a_{n+1} f\left(x_{n+1}\right)$ and summing from $N$ to $n-1$ again, we have

$$
\sum_{s=N}^{n-1} \frac{\varphi_{s+1}}{a_{s+1} f\left(x_{s+1}\right)} \Delta\left(a_{s} \Delta x_{s}\right) \leqslant \sum_{s=N}^{n-1} \frac{\varphi_{s+1}}{a_{s+1}}\left(q_{s}-p_{s}\right) .
$$

Namely,

$$
\begin{gathered}
\frac{\varphi_{n} \Delta x_{n}}{f\left(x_{n}\right)}-\frac{\varphi_{N} \Delta x_{N}}{f\left(x_{N}\right)}-\sum_{s=N}^{n-1} a_{s} \Delta x_{s} \Delta\left(\frac{\varphi_{s}}{a_{s} f\left(x_{s}\right)}\right) \\
\leqslant \sum_{s=N}^{n-1} \frac{\varphi_{s+1}}{a_{s+1}}\left(q_{s}-p_{s}\right) .
\end{gathered}
$$

As $\left\{a_{n}\right\}$ is a nondecreasing sequence, we get

$$
\Delta\left(\frac{\varphi_{s}}{a_{s} f\left(x_{s}\right)}\right)=\frac{\varphi_{s+1}}{a_{s+1} f\left(x_{s+1}\right)}-\frac{\varphi_{s}}{a_{s} f\left(x_{s}\right)} \leqslant \frac{\Delta \varphi_{s}}{a_{s+1} f\left(x_{s+1}\right)} .
$$

Thus

$$
a_{s} \Delta x_{s} \cdot \Delta\left(\frac{\varphi_{s}}{a_{s} f\left(x_{s}\right)}\right) \leqslant \frac{\Delta x_{s} \Delta \varphi_{s}}{f\left(x_{s+1}\right)} .
$$

From (30), we obtain

$$
\frac{\varphi_{n} \Delta x_{n}}{f\left(x_{n}\right)}-\frac{\varphi_{N} \Delta x_{N}}{f\left(x_{N}\right)}+\sum_{s=N}^{n-1} \frac{\varphi_{s+1}}{a_{s+1}}\left(p_{s}-q_{s}\right) \leqslant \sum_{s=N}^{n-1} \frac{\Delta x_{s} \Delta \varphi_{s}}{f\left(x_{s+1}\right)},
$$

using Lemma 1 and conditions, we have

$$
\sum_{s=N}^{n-1} \frac{\Delta x_{s} \Delta \varphi_{s}}{f\left(x_{s+1}\right)} \leqslant M \sum_{s=N}^{n-1} \frac{\Delta x_{s}}{f\left(x_{s+1}\right)} \leqslant M \int_{x_{N}}^{+\infty} \frac{d u}{f(u)}, \quad M>0 .
$$

By letting $n \rightarrow \infty$, we see that the left-hand side of (33) is bounded, this is contrary to our condition $\left(\mathrm{H}_{9}\right)$. The proof is complete.

By means of proof of Theorem 13, we get

Corollary 14. If $\left(H_{1}\right),\left(H_{3}\right)$, and $\left(H_{9}\right)$ hold, $\left\{a_{n}\right\}$ is a nondecreasing sequence, $f(x)$ is a nondecreasing function, and there is a nonnegative sequence $\left\{\varphi_{n}\right\},\left\{\Delta \varphi_{n}\right\}$ is bounded, and $0<\int_{0}^{\varepsilon} d u / f(u)<+\infty$ for $\varepsilon>0$. Then, (3) cannot have any eventually positive nondecreasing bounded solutions.
Corollary 15. Suppose $\left(H_{1}\right),\left(H_{3}\right)$, and $\left(H_{9}\right)$ hold, $\left\{a_{n}\right\}$ is a nondecreasing sequence, $f(x)$ is a nondecreasing function, and there is a nonnegative nonincreasing sequence $\left\{\varphi_{n}\right\}$. Then, (3) cannot have any eventually positive monotone increasing solutions.

Theorem 16. Suppose $\left(H_{1}\right),\left(H_{3}\right)$, and $\left(H_{5}\right)$ hold, $f(x)$ is a nondecreasing function, and

$$
\begin{aligned}
& \left(H_{11}\right) \lim \sup _{n \rightarrow \infty} \sum_{k=n_{0}}^{n} 1 / a_{k} \sum_{s=k}^{\infty}\left(p_{s}-q_{s}\right)=+\infty \text { for all } n_{0} ; \\
& \left(H_{12}\right) 0<\int_{\varepsilon}^{+\infty} d u / f(u)<+\infty, \varepsilon>0 .
\end{aligned}
$$

Then, (3) cannot have any eventually positive nondecreasing solutions.

Proof. Assume to the contrary that there exists $N>n_{0}$ such that $x_{n}>0$ and $\Delta x_{n}>0$ for $n>N .\left\{x_{n}\right\}$ is a solution of (3). By means of (3) and $\left(H_{3}\right)$, we get

$$
\frac{\Delta\left(a_{n} \Delta x_{n}\right)}{f\left(x_{n+1}\right)} \leqslant\left(q_{n}-p_{n}\right),
$$

by summing (35) from $N$ to $n-1$, thus

$$
\begin{aligned}
& \frac{a_{n} \Delta x_{n}}{f\left(x_{n+1}\right)}-\frac{a_{N} \Delta x_{N}}{f\left(x_{N+1}\right)}-\sum_{s=N}^{n-1} a_{s+1} \Delta x_{s+1} \Delta\left(\frac{1}{f\left(x_{s+1}\right)}\right) \\
& \leqslant \sum_{s=N}^{n-1}\left(q_{s}-p_{s}\right) .
\end{aligned}
$$

As $f(x)$ is a nondecreasing function, we know $\Delta x_{s+1} \Delta\left(1 / f\left(x_{s+1}\right)\right) \leqslant 0$, so

$$
\sum_{s=N}^{\infty}\left(p_{s}-q_{s}\right) \leqslant \frac{a_{N} \Delta x_{N}}{f\left(x_{N+1}\right)}
$$

In view of Lemma 1 , we see that

$$
\sum_{N=T}^{n} \frac{1}{a_{N}} \sum_{s=N}^{\infty}\left(p_{s}-q_{s}\right) \leqslant \sum_{N=T}^{n} \frac{\Delta x_{N}}{f\left(x_{N+1}\right)} \leqslant \int_{x_{T}}^{x_{n+1}} \frac{d u}{f(u)} .
$$

This contradiction establishes our assertion.

By means of proof of Theorem 16, we obtain the following.

Corollary 17. Suppose $\left(H_{1}\right),\left(H_{3}\right),\left(H_{5}\right)$, and $\left(H_{11}\right)$ hold, $f(x)$ is a nondecreasing function. Then (3) cannot have any eventually positive nondecreasing bounded solutions.

\section{Acknowledgments}

The authors are very grateful to the referee for her/his valuable suggestions. This work is supported by National Science Foundation of China (11271235), Shanxi Province (2008011002-1), Shanxi Datong University (2009-Y-15,2010B-1), Sci-tech Research and Development Projects in Institutions of Higher Education of Shanxi Province (20111117, 20111020), and the Program for international cooperation of Shanxi Province (2010081005). 


\section{References}

[1] A. Andruch-Sobiło and A. Drozdowicz, "Asymptotic behaviour of solutions of third order nonlinear difference equations of neutral type," Mathematica Bohemica, vol. 133, no. 3, pp. 247258, 2008.

[2] R. N. Rath, N. Misra, and S. K. Rath, "Sufficient conditions for oscillatory behaviour of a first order neutral difference equation with oscillating coefficients," Acta Mathematica, vol. 25, no. 1, pp. 55-63, 2009.

[3] S. H. Saker, "Oscillation of second order nonlinear delay difference equations," Bulletin of the Korean Mathematical Society, vol. 40, no. 3, pp. 489-501, 2003.

[4] R. N. Rath, J. G. Dix, B. L. S. Barik, and B. Dihudi, "Necessary conditions for the solutions of second order non-linear neutral delay difference equations to be oscillatory or tend to zero," International Journal of Mathematics and Mathematical Sciences, vol. 2007, Article ID 60907, 16 pages, 2007.

[5] B. Karpuz, R. Rath, and S. K. Rath, "On oscillation and asymptotic behaviour of a higher order functional difference equation of neutral type," International Journal of Difference Equations, vol. 4, no. 1, pp. 69-96, 2009.

[6] S. S. Cheng and G. Zhang, "Monotone solutions of a higherorder neutral difference equation," Georgian Mathematical Journal, vol. 5, no. 1, pp. 49-54, 1998.

[7] E. Thandapani, Z. Liu, R. Arul, and P. S. Raja, "Oscillation and asymptotic behavior of second order difference equations with nonlinear neutral terms," Applied Mathematics E-Notes, vol. 4, pp. 59-67, 2004.

[8] H. J. Li and S. S. Cheng, "Asymptotically monotone solutions of a nonlinear difference equation," Tamkang Journal of Mathematics, vol. 24, no. 3, pp. 269-282, 1993.

[9] H. J. Li and S. S. Cheng, "An oscillation theorem for a second order nonlinear difference equation," Utilitas Mathematica, vol. 44, pp. 177-181, 1993. 


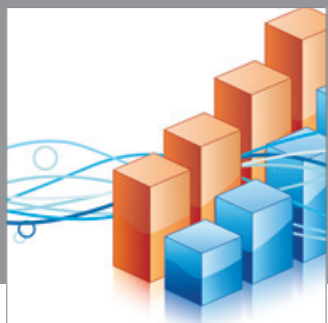

Advances in

Operations Research

mansans

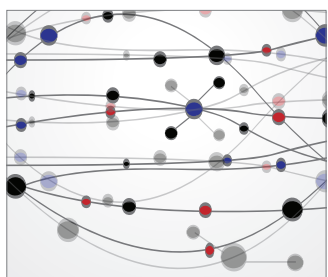

The Scientific World Journal
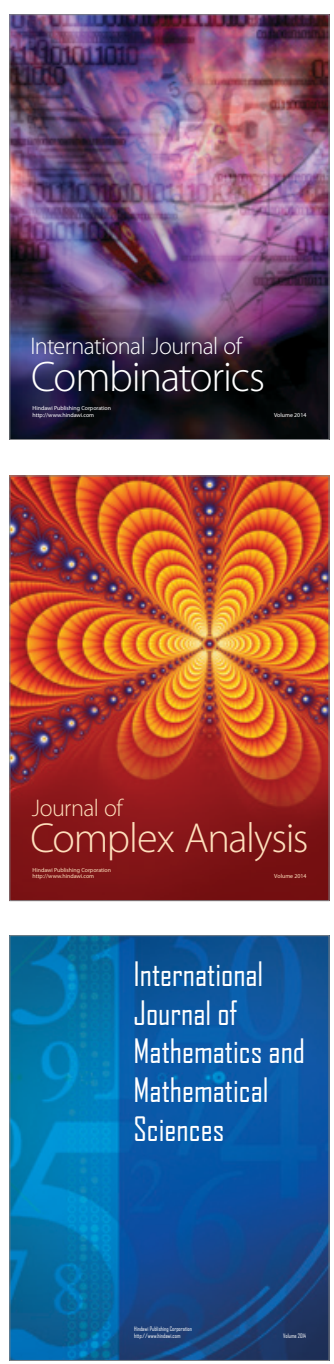
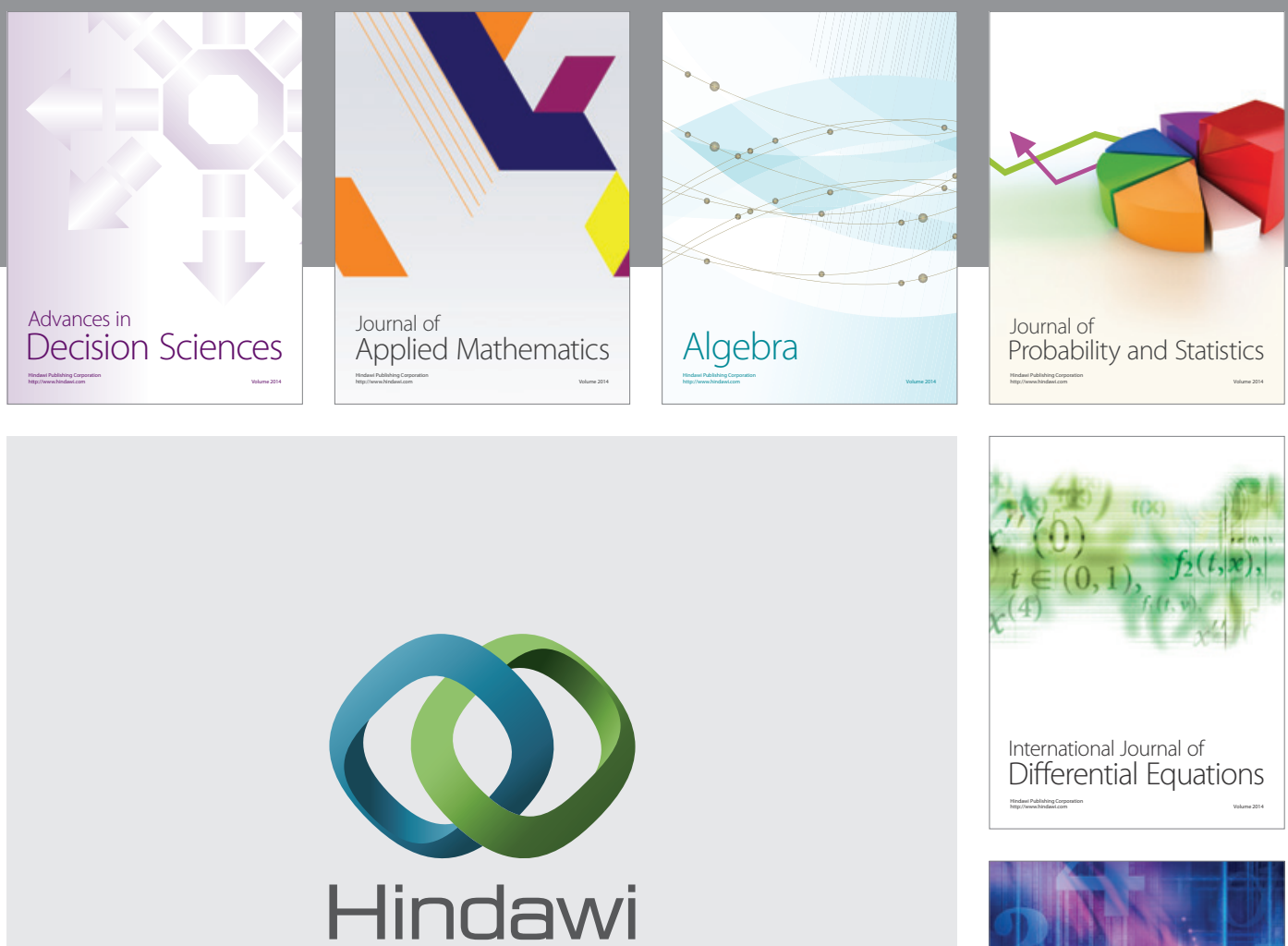

Submit your manuscripts at http://www.hindawi.com
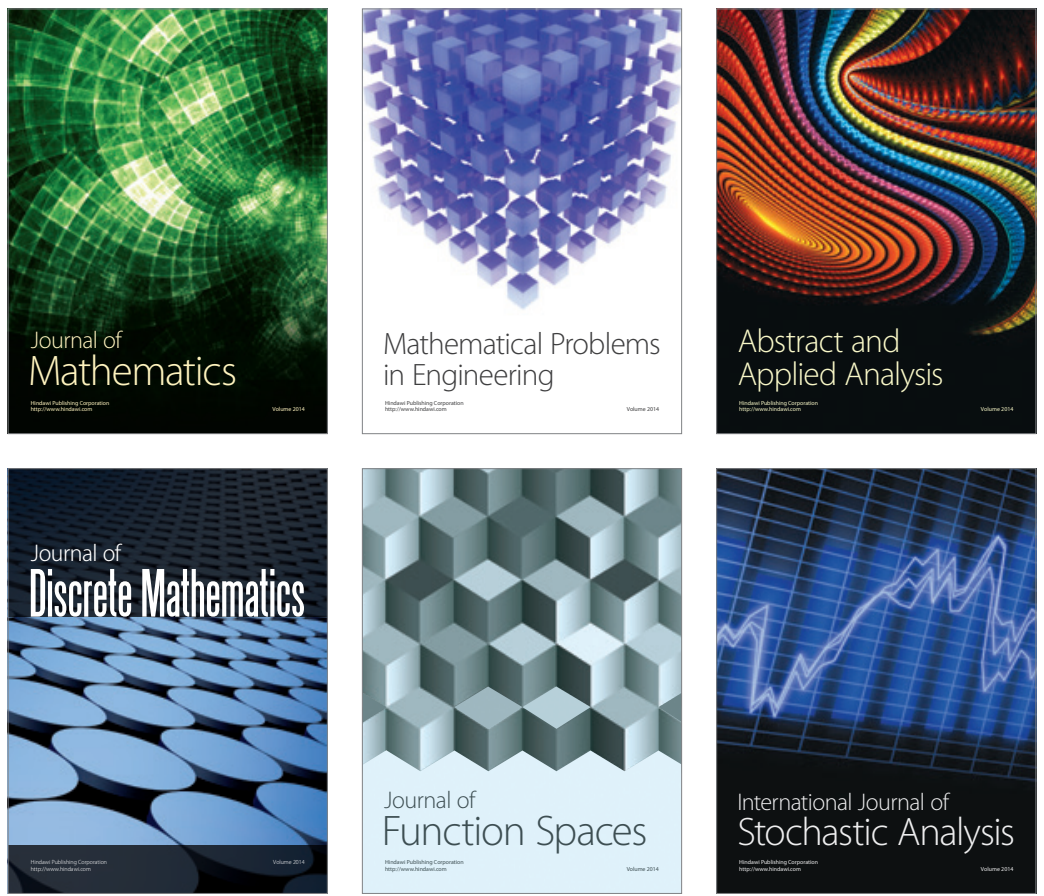

Journal of

Function Spaces

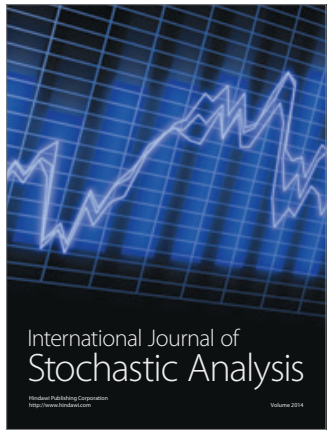

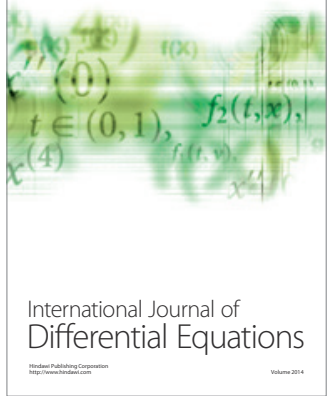
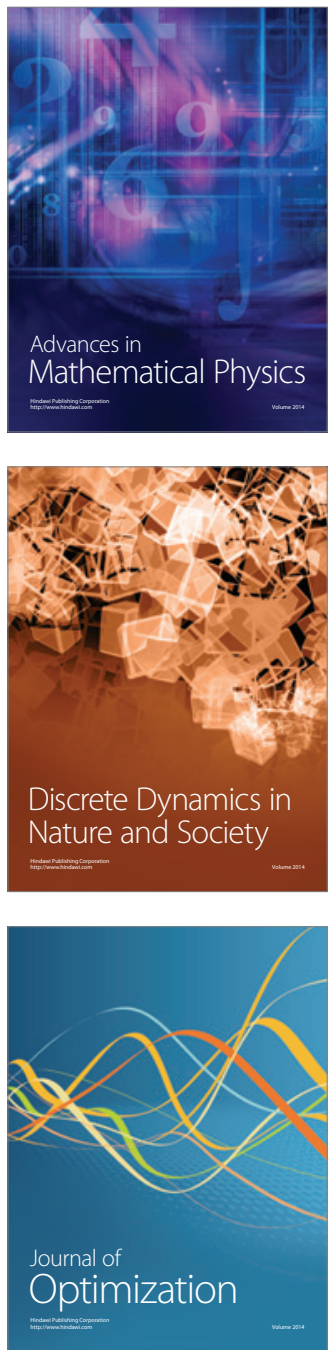